\title{
Analysing Fibre Composite Designs for High-Solidity Ducted Tidal Turbine Blades
}

\author{
Mitchell G. Borg1, Qing Xiao, ${ }^{1, *}$, Steven Allsop², \\ Atilla Incecik $^{1}$, Christophe Peyrard ${ }^{3}$ \\ University of Strathclyde ${ }^{1}$, University of Edinburgh ${ }^{2}$, EDF R\&D ${ }^{3}$
}

\section{Abstract}

This study elaborates a one-way fluid-structure interaction numerical model utilised in investigating the structural mechanics concerning the rotor blades comprising a ducted high-solidity tidal turbine. Coupling hydrodynamic outcomes as structural inputs in effort of acknowledging the most applicable setup, distinct designs are investigated, solid blades and cored blades, implementing fibre-reinforced composite materials, analysed within criteria related to blade axial deformation, induced radial strains, and rotor specific mass.

\section{Methodology}

- A fluid-structure interaction framework was developed consisting of a validated rigid blade-resolved hydrodynamic mathematical model coupled with a blade-isolated structural mechanics model [1]

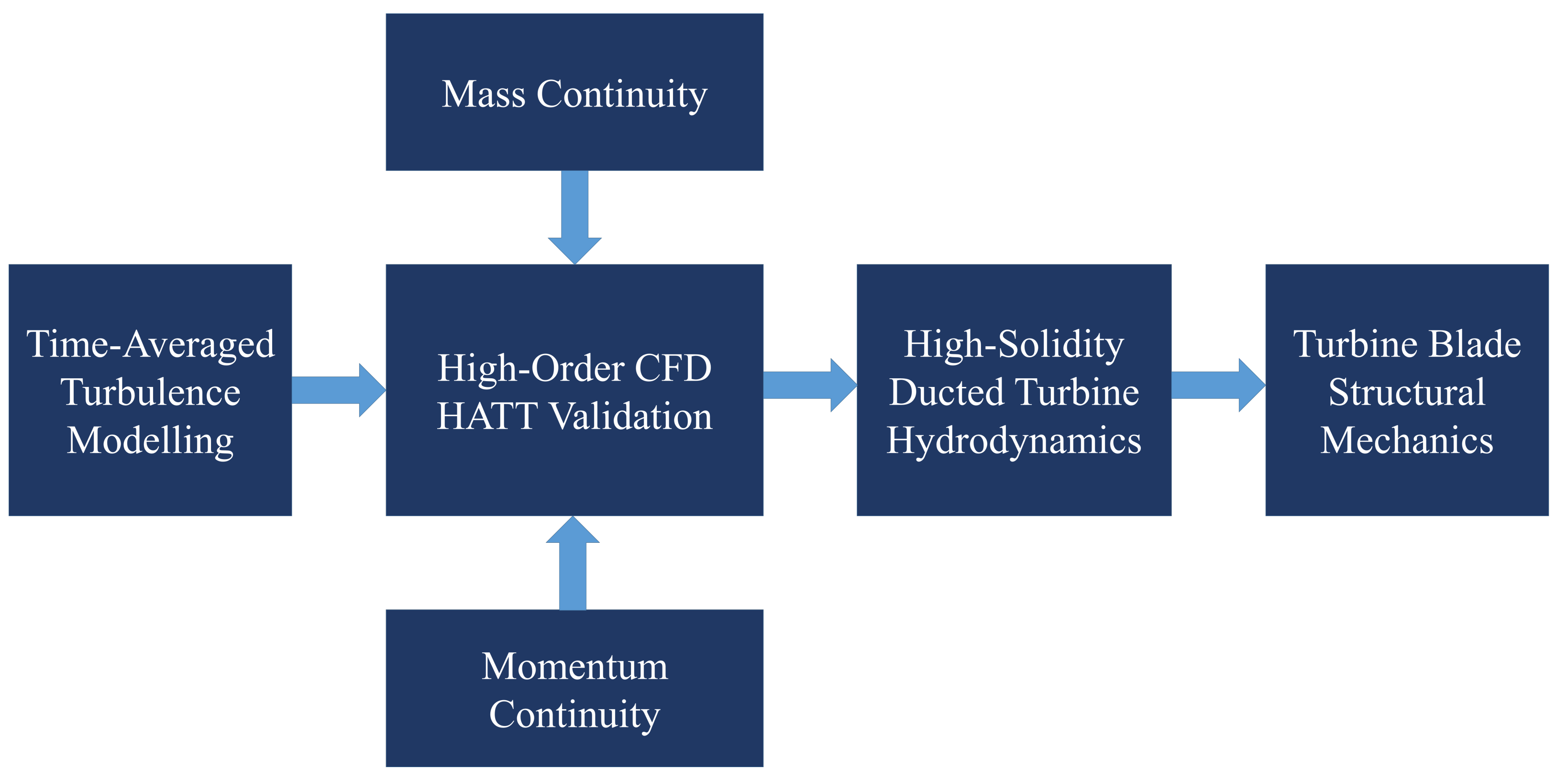

Figure 1: Ducted Turbine Fluid-Structure Interaction Framework Layout

- The real-scale URANS-CFD model was implemented to analyse the hydrodynamic performance of a bidirectional, high-solidity ducted tidal turbine in aligned and yawed flow

Hydrofoil geometry was provided by EDF R\&D; similar to the design of the OpenHydro PS2 device

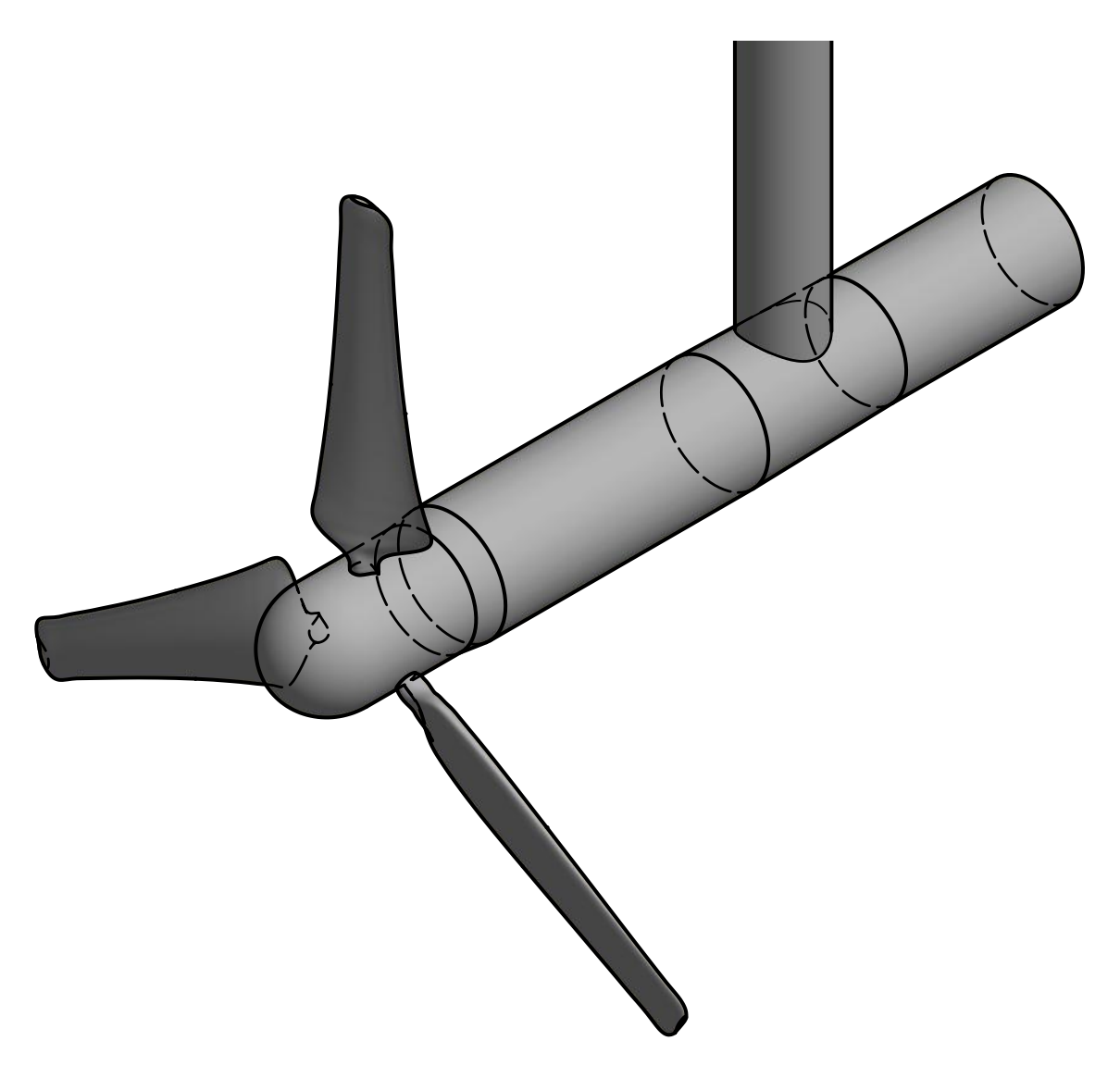

Three-Bladed Horizontal-Axis Turbine [2]

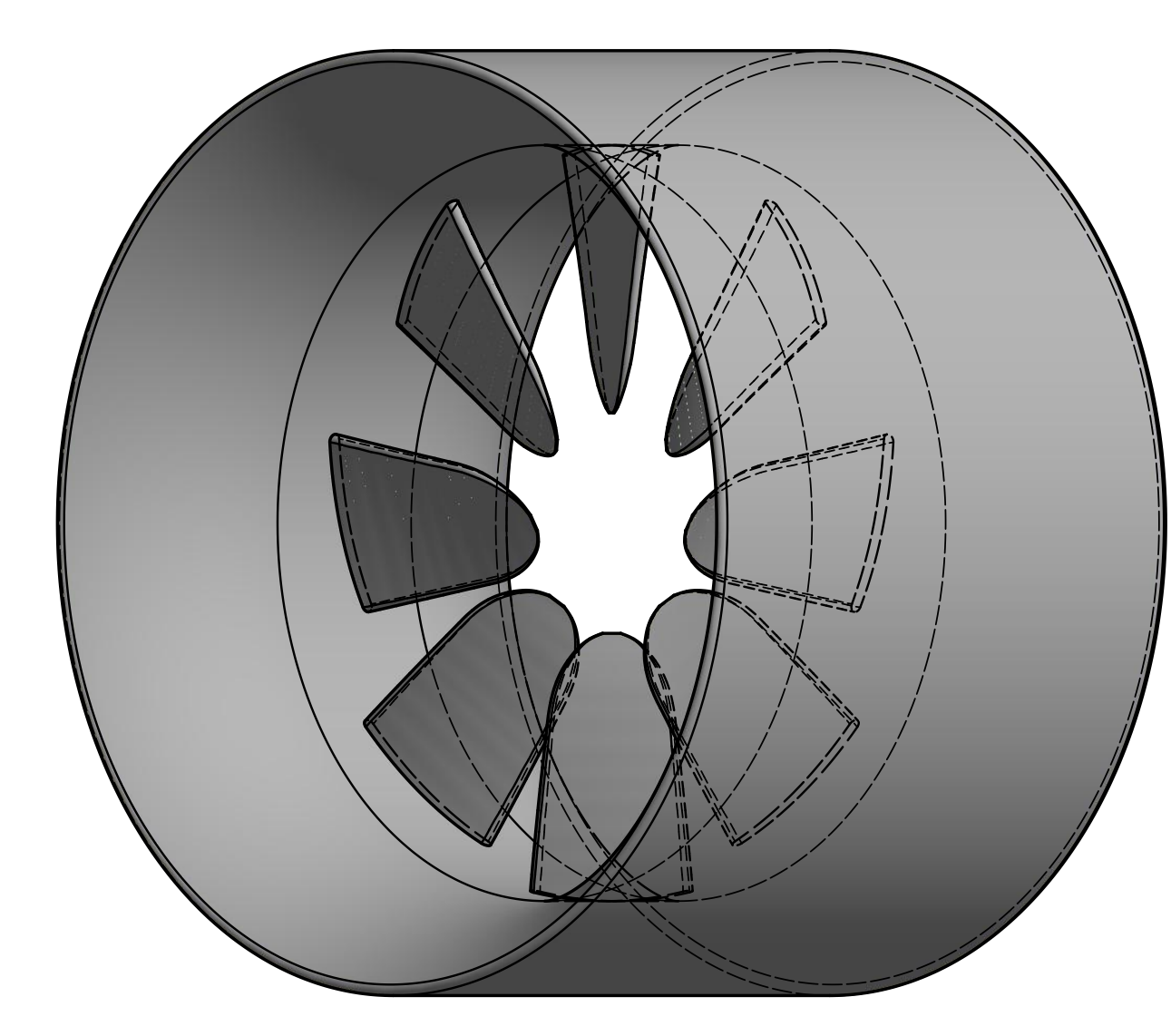

Ducted High-Solidity Turbine
Figure 2: Turbine models utilised for the numerical hydrodynamic analyses

- The 7-equation RSM turbulence model was utilised to close the NavierStokes equation and analyse the anisotropic flow domain

$$
\begin{gathered}
\rho \frac{\partial \tau_{i j}}{\partial t}+\rho U_{k} \frac{\partial \tau_{i j}}{\partial x_{k}}=\frac{\partial}{\partial x_{k}}\left[\left(\mu+\frac{\mu_{T}}{\sigma_{k}}\right) \frac{\partial \tau_{i j}}{\partial x_{k}}\right]-\rho P_{i j}-\rho \Pi_{i j}+ \\
\frac{2}{3} \beta^{*} \rho \omega k \delta_{i j}-2 \rho \omega_{k}\left(\tau_{j m} \epsilon_{i k m}+\tau_{i m} \epsilon_{j k m}\right) \\
\rho \frac{\partial \omega}{\partial t}+\rho U_{j} \frac{\partial \omega}{\partial x_{j}}=\frac{\partial}{\partial x_{j}}\left[\left(\mu+\frac{\mu_{T}}{\sigma_{k}}\right) \frac{\partial \omega}{\partial x_{j}}\right]+\alpha \frac{\rho \omega}{k} \tau_{i j} \frac{\partial U_{i}}{\partial x_{j}}-\beta_{a} f_{\beta} \rho \omega^{2}
\end{gathered}
$$

- The CFD outcomes were employed as boundary condition inputs for the FEA modelling in analysis of the fibre-composite blade designs

Table 1: Material properties adopted in the structural numerical model

Material $\boldsymbol{E}_{\mathbf{1}}(\mathrm{GPa}) \boldsymbol{E}_{\mathbf{2}}(\mathrm{GPa}) \boldsymbol{G}_{\mathbf{1 2}}(\mathrm{GPa}) \boldsymbol{v}_{\mathbf{1 2}}$ Density $\left(\mathrm{kg} \cdot \mathrm{m}^{-3}\right)$ Design

\begin{tabular}{ccccccc}
\hline DB GFRP & 22.0 & 22.0 & 2.7 & 0.30 & 1850 & Solid \\
UD GFRP & 38.8 & 10.0 & 2.7 & 0.30 & 1950 & Cored \\
Corecell & 0.044 & 0.044 & 0.020 & 0.30 & 65 & Cored \\
\hline
\end{tabular}

\section{Results of the Fluid-Structure Interaction}

- The resultant pressure distribution along the turbine blades was primarily evaluated via the high-order hydrodynamic URANS-CFD analyses

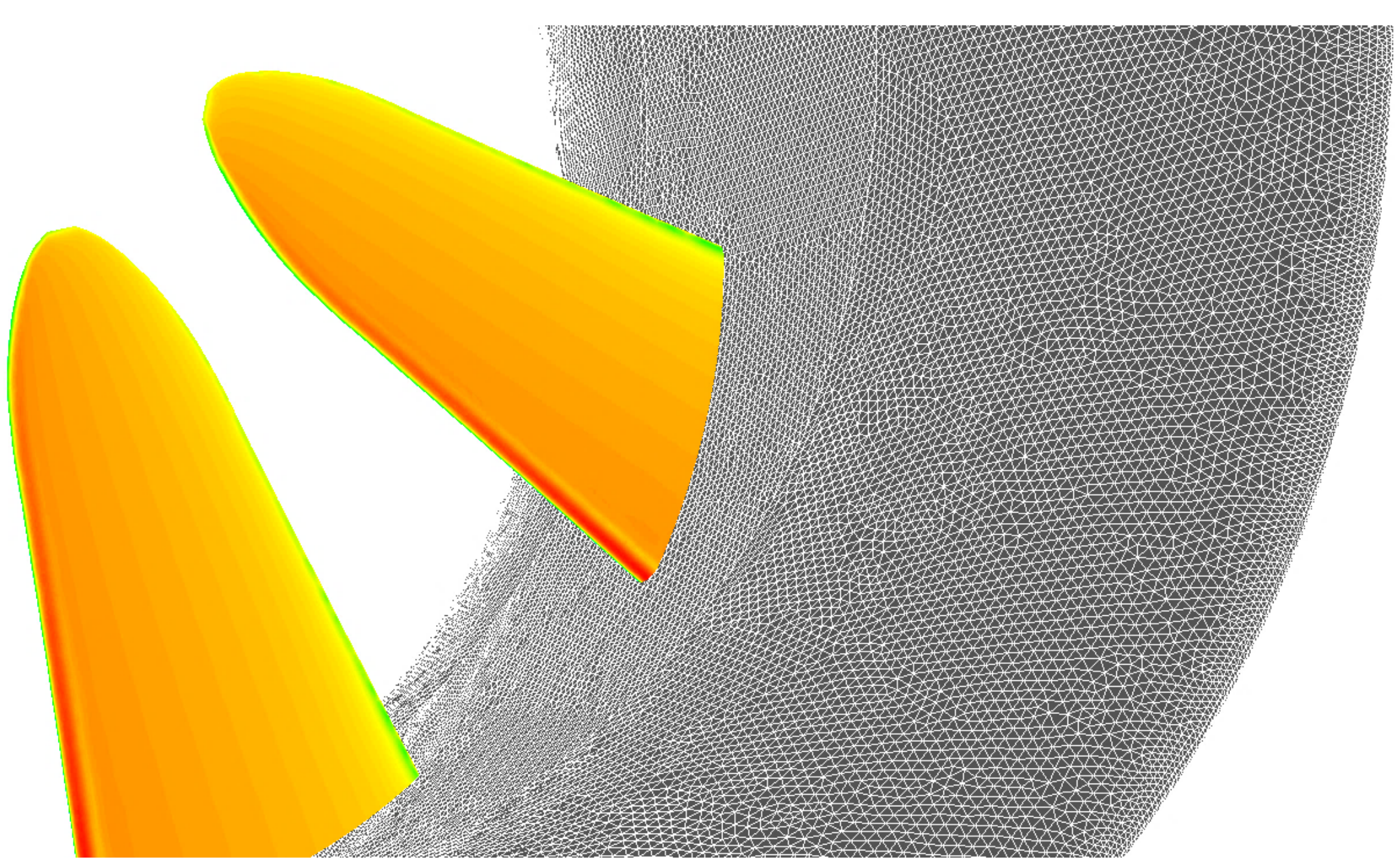

Figure 3: Pressure Distribution along the Turbine Blades; $\boldsymbol{U}_{\infty}=4 \mathrm{~m} . \mathrm{s}^{-\mathbf{1}}, \boldsymbol{T S R}=1.75$

- By transferring the pressure distribution data, the structural response of the solid and cored blades was established within the considered TSR range
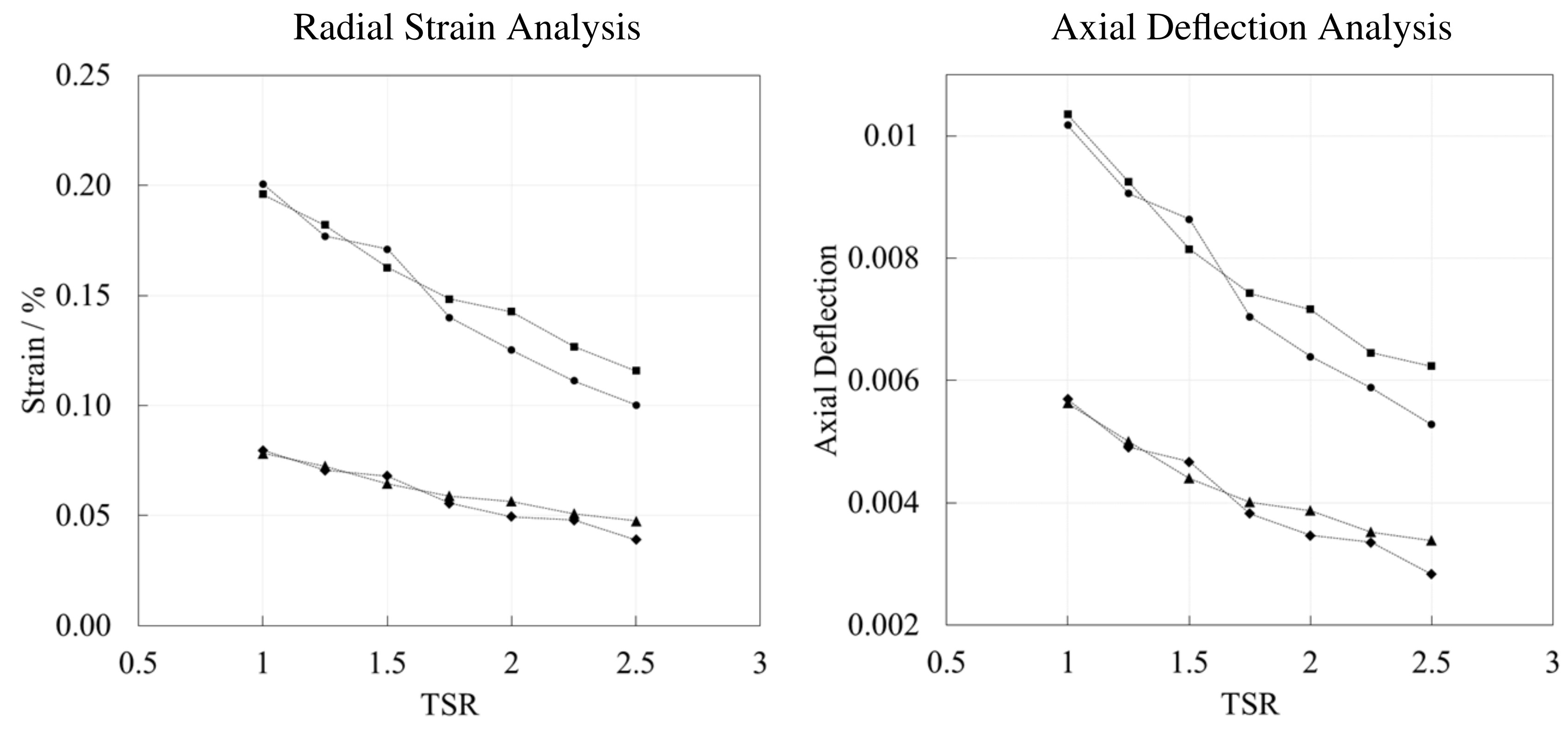

$\bullet$ Solid Blade (Aligned Flow) $\bullet$-Solid Blade (Yawed Flow) $\bullet$ Cored Blade (Aligned Flow) $・$ Cored Blade (Yawed Flow)

Figure 4: Structural Response of the Ducted Turbine Blades in Aligned and Yawed Flows

- A qualitative analysis of the response was carried out on the surfaces of the blades to acknowledge the strain distribution and deflection orientation

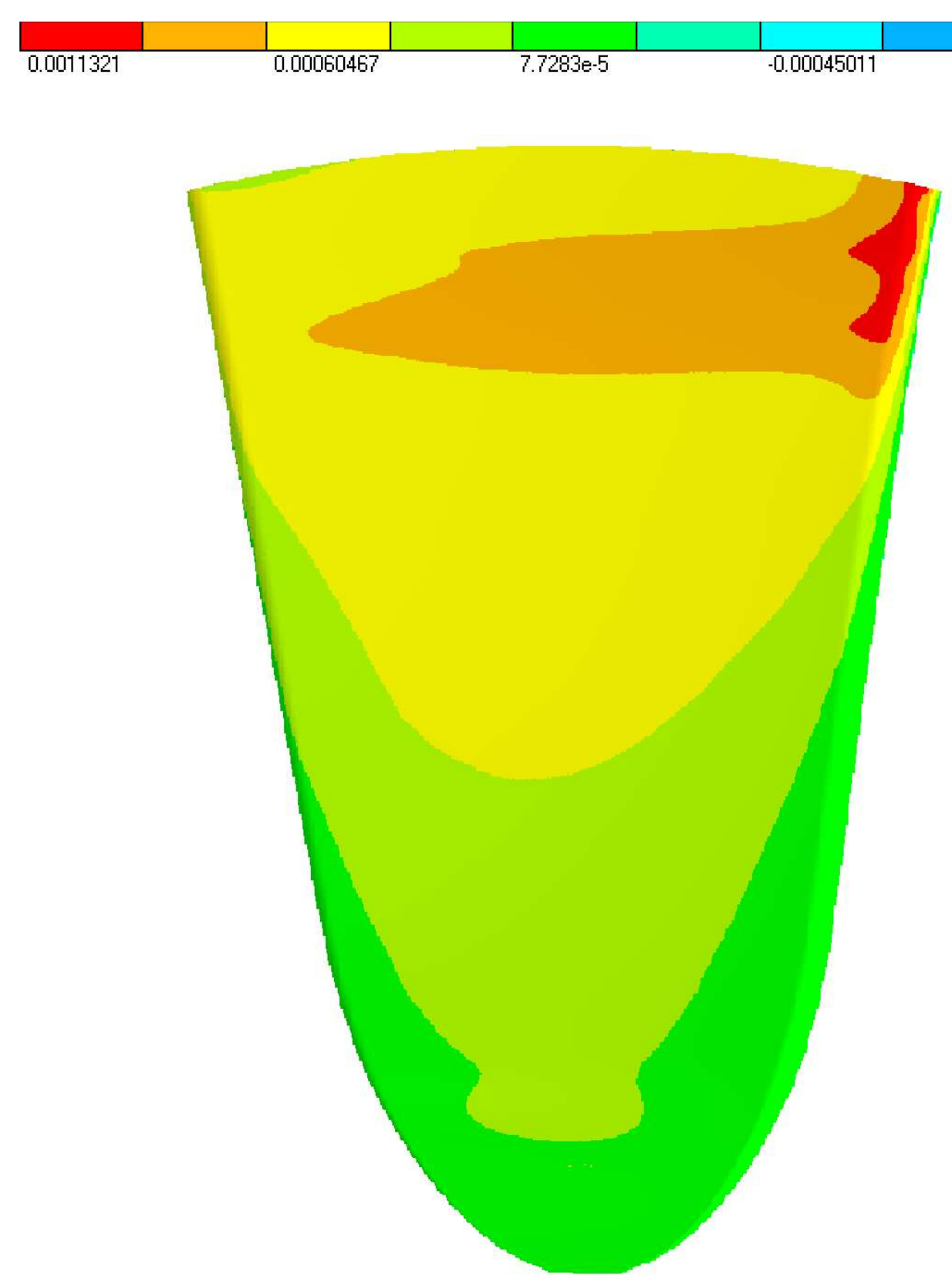

Radial Strain Analysis

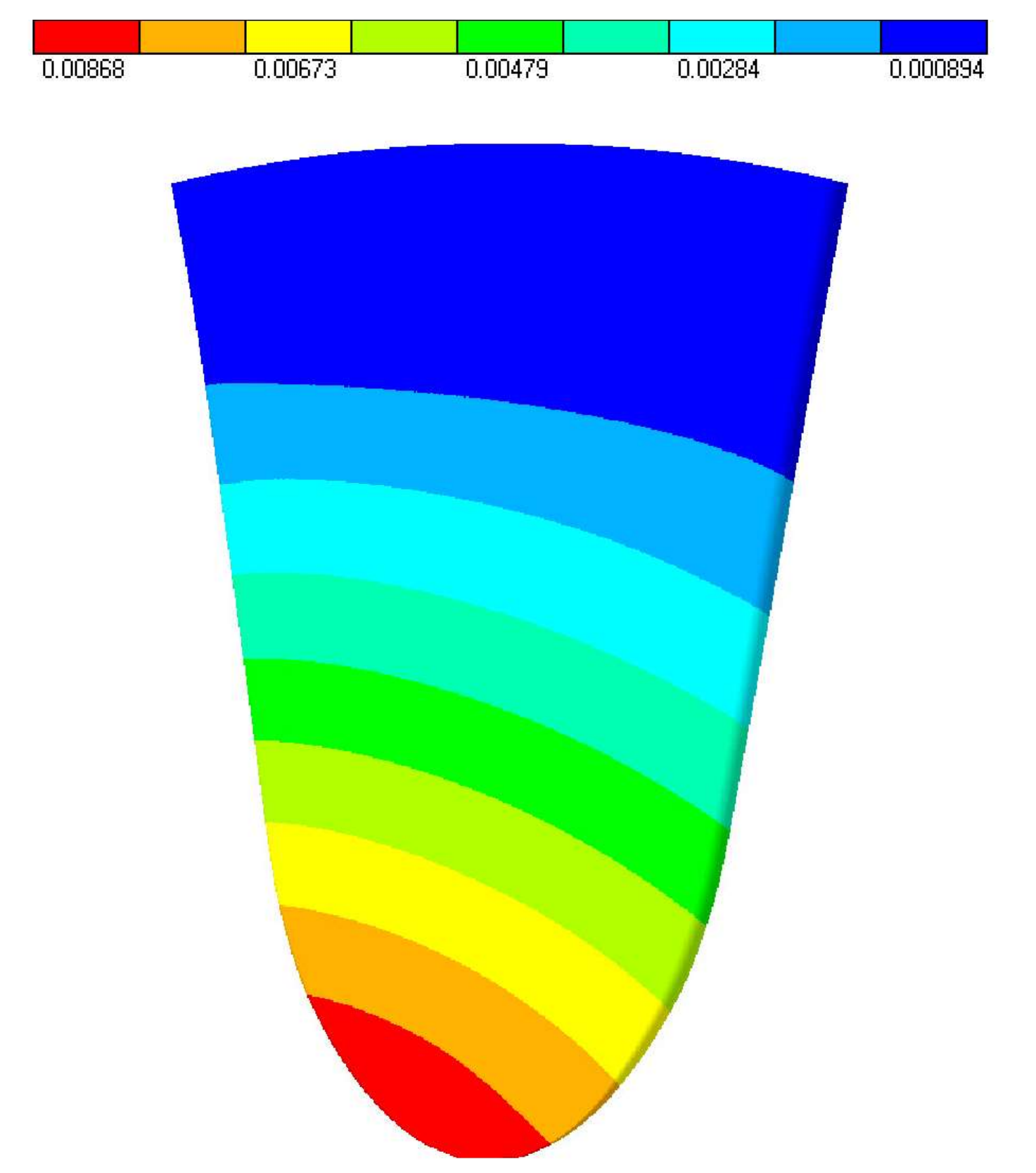

Axial Deflection Analysis
Figure 5: Radial Strain and Axial Deflection Blade Analysis; $\boldsymbol{U}_{\infty}=4 \mathrm{~m} . \mathrm{s}^{\mathbf{- 1}}, \boldsymbol{T S R}=1.75$

Conclusions \& Evaluation of the Blade Design

- The outcomes depicted approximately double the axial deflection for a cored blade, with four times the degree of strain, and a fourth of the specific mass in comparison to a solid blade

- In consideration that the blade response of the cored design is within its structural property limits, the cored blade was established to be the preferred design

[1] M. G. Borg, Q. Xiao, A. Incecik, S. Allsop, and C. Peyrard, "A Numerical Performance Analysis of a Ducted High-Solidity Tidal Turbine," Renewable Energy (under review).

[2] P. Mycek, B. Gaurier, G. Germain, G. Pinon, and E. Rivoalen, "Experimental Study of the Turbulence Intensity Effects on Marine Current Turbines Behaviour," Renewable Energy, vol. 66, pp. 729-746, 2014. 